\title{
Management of Coagulopathy during Bleeding and Invasive Procedures in Patients with Liver Failure
}

\author{
Andreas Drolz ${ }^{a}$ Arnulf Ferlitsch ${ }^{b, c}$ Valentin Fuhrmann ${ }^{a, d}$ \\ a Department of Intensive Care Medicine, University Medical Center Hamburg-Eppendorf, Hamburg, Germany; \\ ${ }^{b}$ Division of Gastroenterology and Hepatology, Department of Internal Medicine III, Medical University of Vienna, Vienna, Austria; \\ 'Department of Internal Medicine I, St. John of God Hospital Vienna, Vienna, Austria; \\ ${ }^{d}$ Department of Medicine B, University of Münster, Münster, Germany
}

\section{Keywords}

Acute liver failure - Anticoagulation - Bleeding ·

Cirrhosis - Portal hypertension

\section{Summary}

Alterations in hemostasis are a characteristic feature of advanced liver disease. Patients with coagulopathy of advanced liver disease are prone to bleedings and also thromboembolic events. Under stable conditions, cirrhosis patients show alterations in both pro- and anticoagulatory pathways, frequently resulting in a rebalanced hemostasis. This review summarizes current recommendations of management during bleeding and prior to invasive procedures in patients with cirrhosis.

(c) 2018 S. Karger GmbH, Freiburg

\section{Introduction}

Alterations in hemostasis are a characteristic feature of advanced liver disease [1-3]. Traditionally, impaired protein synthesis (affecting pro- and anticoagulatory factors), endothelial dysfunction, reduced platelet count/function, and disturbances in fibrinolysis are considered crucial factors contributing to coagulopathy in advanced liver disease $[1,4,5]$. Additionally, portal hypertension is a major contributor to bleeding risk in patients with cirrhosis [4]. However, patients with coagulopathy of advanced liver disease are not only prone to bleedings but also to thromboembolic events [2]. Factors associated with the pro- and anticoagulatory potential in patients with advanced liver disease are shown in table $1[2,4]$.
Thus, despite these abnormalities in hemostasis and global coagulation tests suggesting impaired coagulation, cirrhosis patients - at least under stable conditions - show alterations in both proand anticoagulatory pathways, frequently resulting in a rebalanced hemostasis (fig. 1) [2].

Accordingly, global coagulation tests, such as international normalized ratio (INR), are insufficient to assess the coagulation system and bleeding risk in these patients $[4,6,7]$.

Compared to patients without liver disease, however, this balance in hemostasis is relatively unstable. Especially bacterial infections and renal failure can lead to severe hemostatic alterations with consecutive bleeding diathesis in cirrhosis patients [1]. Therefore, risk for bleeding in cirrhosis seems to be particularly elevated in patients during decompensation, infections, or acute-on-chronic liver failure (ACLF).

\section{Epidemiology and Clinical Impact of Bleedings in Cirrhosis in the Intensive Care Unit}

Bleedings are still a frequent complication in cirrhosis patients and a common cause for intensive care unit (ICU) admission. According to the literature, the incidence of bleedings on ICU admission ranges between 15 and $61 \%$. New onset of major bleeding in the ICU was found in $17-20 \%$ of cirrhosis patients $[7,8]$.

Upper gastrointestinal bleeding is by far the most frequent site of major bleeding in cirrhosis and is usually related to esophageal and/or gastric varices.

Data on procedure-associated bleeding complications in cirrhosis patients are scarce. However, recently it has been shown that up to $5 \%$ of cirrhosis patients in the ICU develop major bleedings related to surgery/invasive procedures during the ICU stay [7].

\section{KARGER}

() 2018 S. Karger GmbH, Freiburg
PD Dr. med. Valentin Fuhrmann 
Table 1. Pro- and anticoagulatory factors in patients with end-stage liver disease

\begin{tabular}{cll}
\hline & $\begin{array}{l}\text { Increased } \\
\text { bleeding risk }\end{array}$ & $\begin{array}{l}\text { Increased risk for } \\
\text { thrombosis/ } \\
\text { thromboembolism }\end{array}$ \\
\hline $\begin{array}{c}\text { Primary } \\
\text { hemostasis }\end{array}$ & $\begin{array}{l}\text { platelet count } \downarrow \\
\text { functional defects } \\
\text { nitric oxide } \uparrow \\
\text { prostacyclin } \uparrow\end{array}$ & $\begin{array}{l}\text { vWF levels } \uparrow \\
\text { ADAMTS } 13 \downarrow\end{array}$ \\
\hline $\begin{array}{c}\text { Secondary } \\
\text { hemostasis }\end{array}$ & $\begin{array}{l}\text { factor I, II, V, VII, IX, X } \\
\text { levels } \downarrow\end{array}$ & $\begin{array}{l}\text { antithrombin } \downarrow \\
\text { protein C and } \downarrow \downarrow \\
\text { factor VIII levels } \uparrow \\
\text { heparin cofactor } 2 \downarrow\end{array}$ \\
\hline $\begin{array}{c}\text { Fibrinolysis } \\
\text { t-PA activity } \uparrow / \text { PAI-1 } \downarrow\end{array}$ & plasminogen $\downarrow$ \\
& factor XIII levels $\downarrow$ & \\
\hline TAFI $\downarrow$ & a2 antiplasmin $\downarrow$ & \\
\hline Hemodynamic & portal pressure $\uparrow$ & $\begin{array}{l}\text { portal venous blood flow } \downarrow \\
\text { venous stasis due to } \\
\text { immobilization }\end{array}$ \\
\hline
\end{tabular}

vWF = von-Willebrand factor; ADAMTS 13 = a disintegrin and metalloproteinase with a thrombospondin type 1 motif, member 13 ; t-PA = tissue plasminogen activator; PAI-1 = plasminogen activator inhibitor, TAFI = thrombin activatable fibrinolysis inhibitor.

Presence of bleeding is associated with high morbidity and mortality in cirrhosis, although its management has substantially improved since the introduction of gastric band ligation. The overall mortality of cirrhosis patients admitted to the ICU is still high and ranges between 32 and $66 \%$ in the recent literature [7-14].

\section{Diagnosis}

The diagnosis of bleeding is usually based upon clinical signs (e.g. hematemesis, melena, obvious bleeding from puncture sites or surgical wounds) and laboratory (e.g. drop in hemoglobin, hematocrit, etc.), or may be diagnosed in the course of imaging procedures (e.g. sonography, computed tomography). If (upper) gastrointestinal bleeding is suspected, endoscopic evaluation is required.

\section{Assessment of the Coagulation System in Cirrhosis}

\section{Conventional Laboratory Testing}

Conventional coagulation testing - such as INR, activated partial thromboplastin time (aPTT), fibrinogen levels, and platelet count - are of limited value in patients with liver cirrhosis $[4,15]$. Yet, recent literature suggests that low fibrinogen levels, low platelet count, and increased aPTT are associated with major bleedings in cirrhosis patients in the ICU [7].
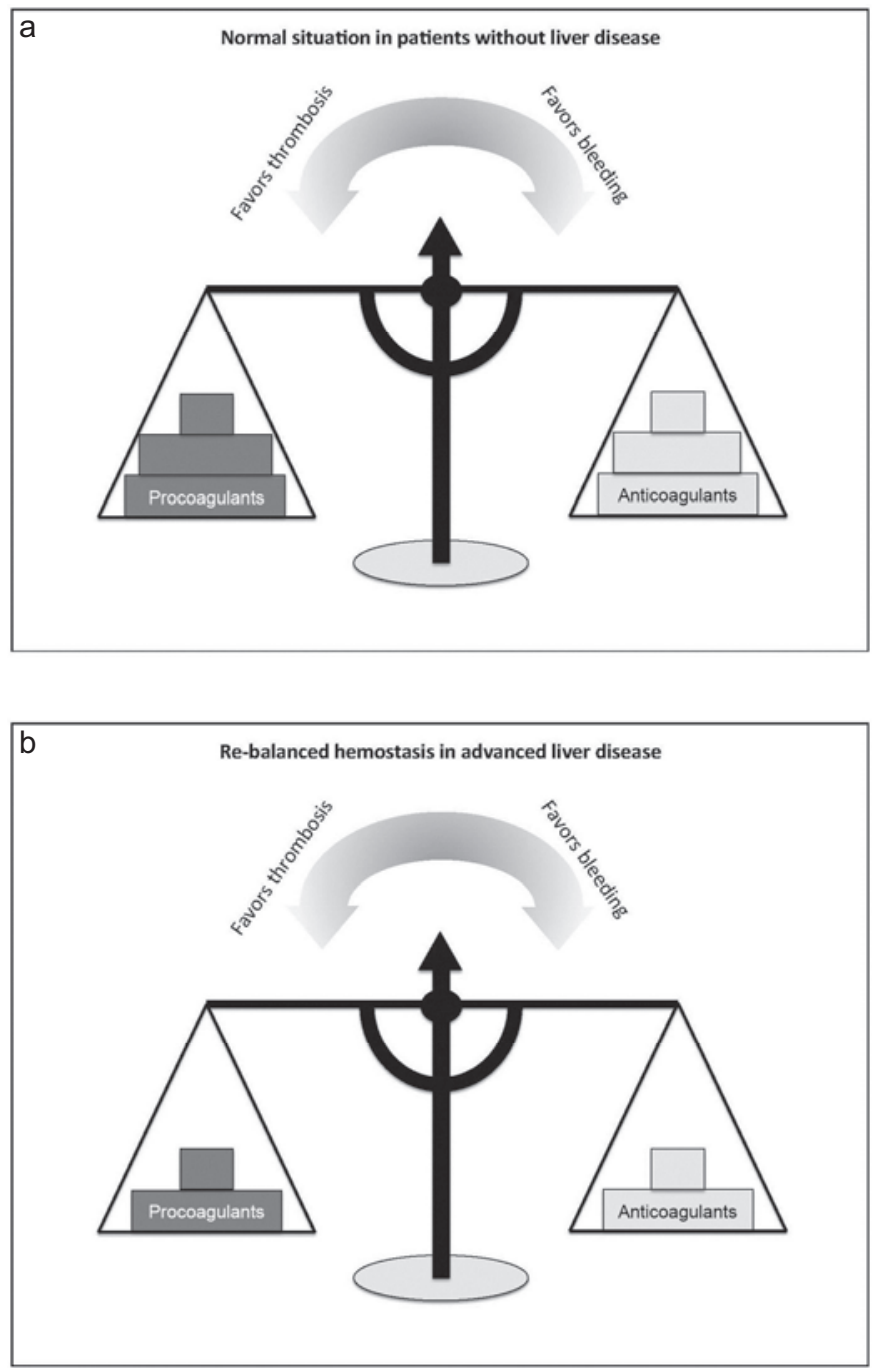

Fig. 1. a, b Concept of (re-)balanced hemostasis in patients with and without liver disease.

\section{Viscoelastic Tests}

Viscoelastic tests such as rotational thrombelastometry $\left(\right.$ ROTEM $\left.^{\circledR}\right)$ and thrombelastography $\left(\mathrm{TEG}^{\circledR}\right)$ are increasingly used to assess coagulation status in end-stage liver disease $[16,17]$. Compared to a conventional coagulation parameter-guided transfusion regimen, a thrombelastography-guided strategy may reduce blood product use prior to invasive procedures in cirrhosis patients without increasing bleeding risk [18]. Moreover, use of a thombelastometry-guided transfusion strategy was associated with lesser use of red packed cells, plasma, and platelets, but higher transfusion rates of fibrinogen, thereby resulting in lower rates of acute renal failure, re-transplantation, and surgical revisions because of bleedings [19]. Yet, all of the mentioned studies have methodological limitations, as they were based on fixed transfusion thresholds derived from conventional coagulation testing, for which evidence is lacking. However, it has been recommended that viscoelastic testing should be considered, especially for periprocedural management [20]. 
Fig. 2. Algorithm for the management of upper gastrointestinal bleedings in patients with advanced liver disease. $\mathrm{APC}=$ Argon plasma coagulation; $\mathrm{GI}=$ gastrointestinal; $\mathrm{NSBB}=$ nonselective beta-blocker; OTSC $=$ over-the-scope clip; PPI $=$ proton pump inhibitor; TIPS $=$ transjugular intrahepatic portosystemic shunt.

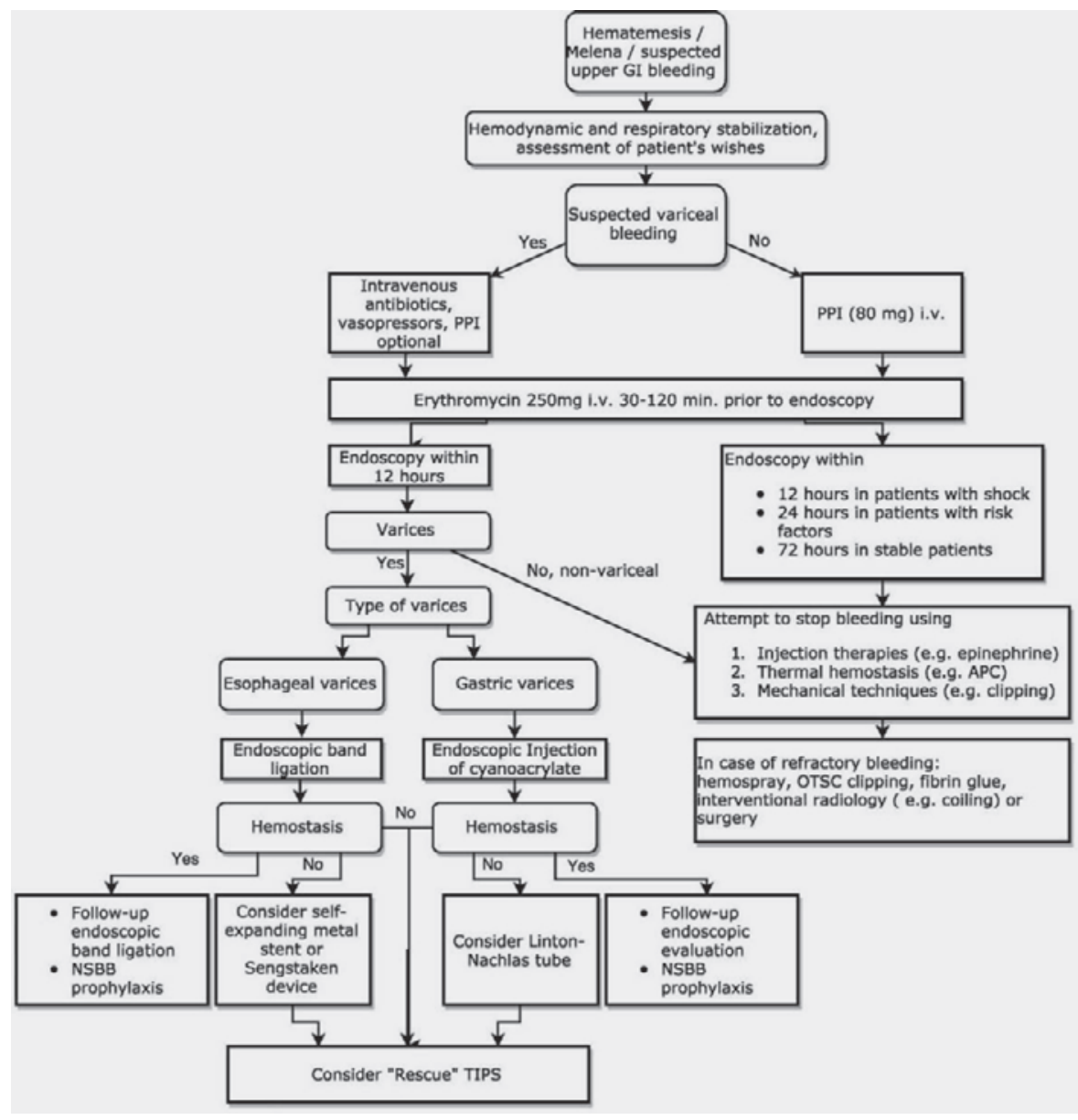

\section{Therapeutic Aspects and Recommendations for Cirrhosis Patients in the Intensive Care Unit}

Most guidelines and consensus recommendations in this field are primarily dealing with the prevention and therapy of variceal bleeding only. Furthermore, data regarding management of hemostasis in cirrhosis patients, especially in the ICU, is limited. Thus, the following recommendations derived from different working groups are mostly eminence-based and primarily related to variceal bleeding.

\section{Prophylactic Measures}

1) Transfusion: In the absence of bleeding or planned invasive procedures, substitution/transfusion of blood or coagulationproducts is not recommended [20,21].

2) Pharmacologic therapy: Non-selective beta-blockers (NSBBs) are a cornerstone of therapy in cirrhosis with significant portal hypertension $[22,23]$. They have been shown to reduce portal hypertension and the risk for variceal hemorrhage in patients with cirrhosis. Yet, over the last years, doubts regarding the use of NSBBs in critically ill cirrhosis patients have been raised as a consequence of potential detrimental effects of NSBBs in cir- rhosis patients with refractory ascites [24] or spontaneous bacterial peritonitis (SBP) [25]. Accordingly, it has been suggested that NSBBs may not be beneficial in cirrhosis patients who develop refractory ascites, hypotension, hepatorenal syndrome, SBP, sepsis, or severe alcoholic hepatitis [26]. While there is no data to support a general ban of beta-blockers in critically ill cirrhosis patients, discontinuation/temporary interruption/ dose reduction of NSBBs has been suggested at the time of SBP, renal impairment, and hypotension [22, 23, 27].

3) Anticoagulation: Data regarding prophylactic anticoagulation in cirrhosis is scarce, and recommendations are partly inconsistent. Some authors advise against using (prophylactic) anticoagulation in cirrhosis [26]. Others suggest using anticoagulation only in patients with occlusive portal vein thrombosis [20]. Yet, at least in the absence of bleeding, there is no data to support withholding anticoagulation from patients with cirrhosis. In general, anticoagulation is safe and well tolerated in cirrhosis $[28,29]$. Moreover, severity of disease, but not anticoagulation was associated with poor outcome in cirrhosis patients with upper gastrointestinal bleeding [30]. In ICU patients with cirrhosis, there was no difference in the incidence of new-onset major bleedings between patients with and without anticoagulation [7]. Thus, the decision on whether or not to use anticoagulation in cirrhosis patients in the ICU remains an individual decision. 


\section{Periprocedural Management}

Following recommendations should be considered prior to and during invasive procedures or surgery [20]:

- hemoglobin transfusion trigger of $7 \mathrm{~g} / \mathrm{dl}$;

- maintaining platelet count $>50 \times 10^{9} / 1$;

- maintaining fibrinogen levels $>1.5 \mathrm{~g} / \mathrm{l}$;

- viscoelastic testing should be considered (but requires further evaluation);

- use of prothrombin complex before invasive procedures, preferably guided by viscoelastic testing.

\section{Management during Bleedings}

\section{General Management}

In accordance with recent guidelines, an algorithm for the general management of upper gastrointestinal bleedings in patients with liver cirrhosis is shown in figure 2 [31].

Moreover, in selected patients with refractory bleedings (e.g. complete portal vein thrombosis), surgical devascularization procedures (e.g. Hassab-Paquet or modified Sugiura procedure) may be life-saving $[32,33]$.

\section{Blood and Hemostasis}

In addition to the aforementioned procedures, monitoring of hemostasis and transfusion of blood and coagulation products remains a major aspect of therapy in cirrhosis patients with bleedings.

During upper gastrointestinal bleeding, a restrictive transfusion strategy (transfusion threshold of $7 \mathrm{~g} / \mathrm{dl}$ ) is associated with higher survival rates than a liberal transfusion strategy (transfusion threshold $9 \mathrm{~g} / \mathrm{dl}$ ) [34]. This applied also to patients with cirrhosis (especially Child-Pugh classes A \& B). Furthermore, there was a trend for reduced incidence of variceal bleedings in patients treated with a restrictive transfusion regimen [34].

Data regarding potential benefits associated with the use of coagulation products during bleeding episodes in cirrhosis are scarce.
However, although only limited evidence is available, the following aspects regarding management of hemostasis during active/persistent (gastrointestinal) bleeding in cirrhosis have recently been recommended for the management of critically ill patients with cirrhosis and also by the German Society of Gastroenterology (DGVS) [20, 31]:

- maintaining platelet count $>50 \times 10^{9} / 1[20,31]$;

- maintaining fibrinogen levels $>1.5 \mathrm{~g} / \mathrm{l}[20]$ or at least $>1 \mathrm{~g} / \mathrm{l}$ [31];

- maintaining prothrombin time $>50 \%[31]$;

- hemoglobin transfusion trigger of $7 \mathrm{~g} / \mathrm{dl}$ [20], maintaining hemoglobin value between 7 and $9 \mathrm{~g} / \mathrm{dl}[31]$;

- antifibrinolytic therapy (tranexamic acid or e-aminocaproic acid) use when hyperfibrinolysis is suspected or proven [20].

However, future studies are required to verify these recommendations and to assess the potential role of viscoelastic testing in cirrhosis patients with acute bleeding [20].

\section{Conclusion}

Bleedings remain a major concern in patients with liver cirrhosis in the ICU. Alterations of hemostasis in cirrhosis are complex, especially during decompensation and ACLF. The extent to which conventional laboratory tests reflect bleeding risk in these patients is unclear. Yet, thresholds for transfusions in response to conventional coagulation tests are part of most available guidelines. Future research efforts should focus on hemostasis in cirrhosis, especially during bleeding and critical illness, in order to improve management of coagulation and outcome in cirrhosis as well as to avoid unnecessary transfusions.

\section{Disclosure Statement}

Andreas Drolz and Arnulf Ferlitsch have nothing to disclose. Valentin Fuhrmann provides presentations for CSL Behring.

\section{References}

1 Caldwell SH, Hoffman M, Lisman T, et al: Coagulation disorders and hemostasis in liver disease: pathophysiology and critical assessment of current management. Hepatology 2006;44:1039-1046.

2 Lisman T, Caldwell SH, Burroughs AK, et al: Hemostasis and thrombosis in patients with liver disease: the ups and downs. J Hepatol 2010;53:362-371.

3 Kaul V, Munoz S: Coagulopathy of liver disease. Curr Treat Options Gastroenterol 2000;3:433-438.

4 Valla D-C, Rautou P-E: The coagulation system in patients with end-stage liver disease. Liver Int 2015; 35(suppl 1):139-144.

5 Hunt BJ: Bleeding and coagulopathies in critical care N Engl J Med 2014;370:847-859.
Townsend JC, Heard R, Powers ER, Reuben A: Usefulness of international normalized ratio to predict bleeding complications in patients with end-stage liver disease who undergo cardiac catheterization. Am J Cardiol 2012;110:1062-1065.

7 Drolz A, Horvatits T, Roedl K, et al: Coagulation parameters and major bleeding in critically ill patients with cirrhosis. Hepatology 2016;64:556-568.

8 Cholongitas E, Senzolo M, Patch D, et al: Risk factors, sequential organ failure assessment and model for endstage liver disease scores for predicting short-term mortality in cirrhotic patients admitted to intensive care unit. Aliment Pharmacol Ther 2006;23:883-893.
9 Majumdar A, Bailey M, Kemp WM, Bellomo R, Roberts SK, Pilcher D: Declining mortality in critically ill patients with cirrhosis in Australia and New Zealand between 2000 and 2015. J Hepatol 2017;67:1185-1193.

10 Levesque E, Saliba F, Ichaï P, Samuel D: Outcome of patients with cirrhosis requiring mechanical ventilation in ICU. J Hepatol 2014;60:570-578.

11 Olmez S, Gümürdülü Y, Tas A, Karakoc E, Kara B, Kidik A: Prognostic markers in cirrhotic patients requiring intensive care: a comparative prospective study. Ann Hepatol 2012;11:513-518.

12 Tu K-H, Jenq C-C, Tsai M-H, et al: Outcome scoring systems for short-term prognosis in critically ill cirrhotic patients. Shock 2011;36:445-450. 
13 Das V, Boelle P-Y, Galbois A, et al: Cirrhotic patients in the medical intensive care unit: early prognosis and long-term survival. Crit Care Med 2010;38:2108-2116.

14 Filloux B, Chagneau-Derrode C, Ragot S, et al: Shortterm and long-term vital outcomes of cirrhotic patients admitted to an intensive care unit. Eur J Gastroenterol Hepatol 2010;22:1474-1480.

15 Violi F, Basili S, Raparelli V, Chowdary P, Gatt A, Burroughs AK: Patients with liver cirrhosis suffer from primary haemostatic defects? Fact or fiction? J Hepatol 2011;55:1415-1427.

16 Saner FH, Kirchner C: Monitoring and treatment of coagulation disorders in end-stage liver disease. Visc Med 2016;32:241-248.

17 Wang S-C, Shieh J-F, Chang K-Y, et al: Thromboelastography-guided transfusion decreases intraoperative blood transfusion during orthotopic liver transplantation: randomized clinical trial. Transplant Proc 2010; 42:2590-2593.

18 De Pietri L, Bianchini M, Montalti R, et al: Thrombelastography-guided blood product use before invasive procedures in cirrhosis with severe coagulopathy: a randomized, controlled trial. Hepatology 2016;63: 566-573.

19 Leon-Justel A, Noval-Padillo JA, Alvarez-Rios AI, et al: Point-of-care haemostasis monitoring during liver transplantation reduces transfusion requirements and improves patient outcome. Clin Chim Acta 2015;446 277-283.
20 Nadim MK, Durand F, Kellum JA, et al: Management of the critically ill patient with cirrhosis: a multidisciplinary perspective. J Hepatol 2016;64:717-735.

21 Olson JC, Wendon JA, Kramer DJ, et al: Intensive care of the patient with cirrhosis. Hepatology 2011;54: 1864-1872.

22 de Franchis R; Baveno VI Faculty: Expanding consensus in portal hypertension: report of the Baveno VI Consensus Workshop: stratifying risk and individualizing care for portal hypertension. J Hepatol 2015;63: $743-752$.

23 Garcia-Tsao G, Abraldes JG, Berzigotti A, Bosch J: Portal hypertensive bleeding in cirrhosis: risk stratification, diagnosis, and management: 2016 practice guidance by the American Association for the study of liver diseases. Hepatology 2017;65:310-335.

24 Sersté T, Melot C, Francoz C, et al: Deleterious effects of beta-blockers on survival in patients with cirrhosis and refractory ascites. Hepatology 2010;52:1017-1022.

25 Mandorfer M, Bota S, Schwabl P, et al: Nonselective $\beta$ blockers increase risk for hepatorenal syndrome and death in patients with cirrhosis and spontaneous bacterial peritonitis. Gastroenterology 2014;146:16801681.

26 Ge PS, Runyon BA: Treatment of patients with cirrhosis. N Engl J Med 2016;375:767-77.

27 Tripathi D, Stanley AJ, Hayes PC, et al: U.K. guidelines on the management of variceal haemorrhage in cirrhotic patients. Gut 2015;64:1680-1704.
28 Amitrano L, Guardascione MA, Menchise A, et al: Safety and efficacy of anticoagulation therapy with low molecular weight heparin for portal vein thrombosis in patients with liver cirrhosis. J Clin Gastroenterol 2010; 44:448-451.

29 Delgado MG, Seijo S, Yepes I, et al: Efficacy and safety of anticoagulation on patients with cirrhosis and portal vein thrombosis. Clin Gastroenterol Hepatol 2012;10: 776-783.

30 Cerini F, Gonzalez JM, Torres F, et al: Impact of anticoagulation on upper-gastrointestinal bleeding in cirrhosis. A retrospective multicenter study. Hepatology 2015;62:575-583.

31 Götz M, Anders M, Biecker E, et al: S2k Guideline Gastrointestinal Bleeding - Guideline of the German Society of Gastroenterology DGVS (Article in German). Z Gastroenterol 2017;55:883-936.

32 Král V, Klein J, Havlík R, Aujeský R, Utíkal P: Esophagogastric devascularization as the last option in the management of variceal bleeding. Hepatogastroenterology 2002;49:244-246.

33 Paquet KJ, Lazar A: The value collateralization and venous obstruction operations in acute bleeding esophageal varices in patients with cirrhosis of the liver (Article in German). Chirurg 1995;66:582-587.

34 Villanueva C, Colomo A, Bosch A, et al: Transfusion strategies for acute upper gastrointestinal bleeding. N Engl J Med 2013;368:11-21. 